\title{
Advancing Knowledge About Developmental and Life-
}

\section{Course Criminology}

Tara Renae McGee, School of Criminology and Criminal Justice, Griffith University

David P. Farrington, Institute of Criminology, Cambridge University

Ross Homel, School of Criminology and Criminal Justice, Griffith University

Alex R. Piquero, Program in Criminology, University of Texas at Dallas

Published in Australian \& New Zealand Journal of Criminology, 2015, Vol. 48(3)

307-313 
Developmental and life-course criminology is concerned mainly with three topics: (1) the development of offending and antisocial behavior from childhood to adulthood; (2) risk and protective factors for offending and antisocial behavior; and (3) the effect of life events on the course of development (Farrington, 2003). A main aim is to study changes within individuals over time in risk factors and life events, and to relate them to later changes in offending. This special issue of the Australian and New Zealand Journal of Criminology brings together a range of papers focused around this aim.

\section{Background}

The impetus for this special issue arose from a one-day Developmental and Life-Course Criminology Symposium that was hosted by Tara Renae McGee at Griffith University on October 4, 2013 immediately after the Australian and New Zealand Society of Criminology annual conference in Brisbane, Australia. McGee invited David Farrington, Alex Piquero and Ross Homel to be speakers at the Symposium and together they developed the themes and the format of the day. McGee also gratefully received funding from the Griffith Social and Behavioral Research College Research Event Support Scheme, which covered the room and catering expenses of the day.

The focus of the Symposium was driven by the research program of McGee's Australian Research Council Discovery Early Researcher Award Fellowship. The goal of this program of research is to advance the field of developmental and lifecourse criminology through a critical examination of extant theories and empirical testing of key postulates.

The goal of the Symposium was to bring together interested researchers to critically examine and discuss the state of knowledge within developmental and life- 
course criminology in terms of development, theory and prevention. It brought together a range of people from Australia, the UK, Europe, and the USA, and included people at all stages of criminological careers from postgraduate students to leading professors.

The Symposium was divided into three sessions which each focused on a different element of developmental and life-course criminology. At the start of each session there was a speaker who acted as a protagonist and presented on the theme of the session in a manner that was designed to stimulate discussion. In the first session, David Farrington gave a presentation about what we know and what we need to know about the development of offending over the life-course. In the second session, Alex Piquero gave a presentation on what we know and what we need to know about developmental and life-course theories. The final protagonist was Ross Homel, who gave a presentation on what we know and what we need to know about the prevention of offending. The presentations, informed by the subsequent discussions of themes at the Symposium, form the basis for the first three papers of this special issue.

After the symposium, David Farrington contacted the editors of the Australian and New Zealand Journal of Criminology and proposed this special issue to record and disseminate the ideas presented by the three protagonists, Farrington, Piquero, and Homel, and to present results from some major Australian and New Zealand longitudinal studies. Key developmental and life-course researchers from Australia and New Zealand were asked to focus especially on the following three themes:

1. The development of offending and antisocial behavior;

2. Developmental correlates and risk and protective factors for offending and antisocial behavior; and 
3. Effects of life events and life transitions on offending and antisocial behavior.

4. Implications for prevention and policy

This special issue contains papers from four Australian studies and one New Zealand study.

\section{Contents}

In the first article, David Farrington reviews prospective longitudinal surveys of offending and their advantages and problems. He summarizes knowledge about criminal careers based on official records and self-reports. He documents major individual, family, socio-economic and neighborhood risk factors, and reviews knowledge about intergenerational transmission, cross-national comparisons, and protective factors. He also discusses research on the effects of life events on the course of development of offending. He concludes by recommending some new prospective longitudinal surveys; these will be discussed later in this article.

Alex Piquero then reviews some major developmental and life-course theories of offending. Importantly, he highlights a number of key issues that need to be addressed. These include whether there are different types of offenders; the need to investigate the effects of risk factors at different ages; the role of biological factors, neighborhood contexts, and immediate situational influences; the need for more qualitative and quantitative research on the effects of life events; and the need to study diverse populations.

In the first of the articles from major longitudinal surveys, Tara Renae McGee and her colleagues present data from the Australian Mater-University Study of Pregnancy and its Outcomes (MUSP), which is a longitudinal study of mother-child pairs in Brisbane from the pre-natal stage to 21 years of age. They investigate 
Moffitt's concept of snares, which are factors that may lead to an adolescent persisting in antisocial behavior such as drug addiction, educational failure, and contact with the justice system. They found that one third of individuals identified as having an adolescent onset of antisocial behavior persisted with this antisocial behavior as young adults. They concluded that this continuity can, in part, be explained by snares and that reducing exposure to snares may lead to less antisocial behavior in adulthood.

Ross Homel then describes a community-based developmental prevention program and associated capacity building study using the CREATE model that was developed as an outcome of the Pathways to Prevention Project that operated in a disadvantaged region of Brisbane between 2002 and 2011. CREATE is an acronym: Collaborative; Relationships-driven; Early in the pathway; Accountable; Trainingfocused; Evidence-driven. The aim in this project is to build the capacity for schools and community agencies to deliver goal-directed, quantitatively evaluated, evidencebased resources that promote child wellbeing and prevent antisocial and criminal behaviors.

David Fergusson and his colleagues then summarize results from the Christchurch Health and Development Study (CHDS), which is a longitudinal study of a birth cohort of 1265 children who were born in Christchurch, New Zealand, in 1977. This cohort has now been studied from birth to the age of 35. Their research shows that conduct problems in childhood predict later criminal offending in adolescence and early adulthood, the MAOA genotype in conjunction with childhood maltreatment and certain environmental conditions predicts later offending, and the analysis of criminal trajectories. They also specify how this longitudinal survey has 
played a critical role in the development of two early prevention programs in New Zealand.

Anna Stewart and her colleagues then describe longitudinal analyses based on linked administrative data in Queensland. They conclude that Indigenous Australians are over-represented among those who have had contact with the criminal justice system and among incarcerated populations, and that childhood maltreatment predicts later offending. They also study adult-onset offenders and the monetary costs of the criminal careers of chronic offenders.

Finally, Sheryl Hemphill and her colleagues report innovative analyses that compare between-individual and within-individual correlates and predictors of antisocial behavior. Most research in criminology investigates causes by making comparisons between individuals, but the concept of cause requires that changes within individuals in a risk factor are followed by changes in antisocial behavior. They analyze a state-wide representative sample of 927 students in Victoria, Australia, as part of the International Youth Development Study. They find that within-individual relationships with antisocial behavior are often different from between-individual relationships, and recommend more research on this topic.

\section{What Do We Need To Know, and How Can We Find Out?}

A key issue is to advance knowledge about the causes and prevention of offending. As just mentioned, a variable $\mathrm{X}$ causes offending if changes in $\mathrm{X}$ within individuals are followed by changes in offending within individuals. However, most knowledge about causes in criminology is based on comparisons between individuals, for example showing that unemployed people are more likely to offend than employed people. A major problem of interpretation is that unemployed people differ from employed people in numerous respects (on numerous measured and unmeasured 
variables), and any differences between them in offending may be caused by differences in some variable other than unemployment.

A major advantage of longitudinal studies is that they make it possible to investigate within-individual changes over time. For example, offending by individuals during periods of unemployment can be compared with offending by the same individuals during periods of employment (Farrington et al., 1986b). In this analysis, each individual acts as his or her own control and all individual factors are held constant. Therefore, within-individual analyses provide much more convincing evidence than between-individual analyses about causal influences.

There is a great need for new prospective longitudinal studies, especially in Australia and New Zealand, with regular, repeated (preferably face-to-face) assessments that would permit within-individual analyses relating changes in risk/protective factors or life events to later changes in offending. This would enormously advance knowledge about the causes of offending. Also, it would be desirable to carry out coordinated longitudinal studies following both community and offender samples.

A key priority in criminology is to measure self-reported and official offending from childhood to adulthood. This would require regular, repeated interviews at different ages, seen to best advantage in the pioneering Pittsburgh Youth Study (Loeber et al., 2008). It is very important to estimate the "scaling-up” factor from official to self-reported offending for different types of crimes and people at different ages, not only to assess the effectiveness of the police and courts but also to assess the true effectiveness of intervention programs that generally have only official measures of recidivism. This is particularly important for cost-benefit analyses (Farrington and Koegl, 2015). It is also essential to maximize response rates, because 
the most elusive and uncooperative people (who are the hardest to include in surveys) tend to be the most antisocial and criminal (Farrington et al., 1990).

It is important to conduct research on biological and neighborhood/community factors in longitudinal studies as well as on the more traditional individual, family, peer, and school factors. In order to investigate some biological and/or genetic factors, special designs may be needed, such as following up monozygotic and dizygotic twins. Historically genetic research has focused on single gene association studies, examining for example, the association between MAOA and aggression (Caspi et al., 2002). What are needed now, and only just beginning to emerge, are genome wise association studies (GWAS) that are able to take into account individual, family, peer, and school factors.

It is also particularly important to study situational factors in longitudinal studies, to explain both the development of offenders and the commission of offenses. Longitudinal studies should be designed not only to explain how offenders develop but also to explain how and why the potential offender commits the actual crime in the situation.

More research is needed on risk factors, in order to investigate independent, interactive and mediating factors, and to try to establish what are the distinct underlying theoretical constructs. It is important to study continuity or discontinuity in offending over time, and to search for factors that might prevent children from criminogenic backgrounds from becoming offenders. It is desirable to study the intergenerational transmission of offending, and it is important to search for factors that might interrupt intergenerational transmission.

While a great deal is known about risk factors for offending, there is a particular need to study protective factors in new longitudinal studies. These can be 
defined as factors that predict a low rate of offending, factors that predict a low rate of offending in a risk category (e.g. low income), or factors that interact with a risk factor to nullify its influence (Farrington, Loeber, \& Ttofi, 2012). Protective factors also need to be included in risk assessment instruments and targeted in intervention programs.

A major problem with developmental and life-course theories (like other criminological theories) is that they do not make quantitative predictions. Because of this, it is rare for any criminological theory to be disproved. It would be desirable for theories to build on simple mathematical models that make and test quantitative predictions. For example, MacLeod, Grove, and Farrington (2012) were able to predict many features of criminal careers accurately by assuming that there were only three types of offenders: high-rate (of offending)/high-risk (of reoffending), lowrate/high-risk, and low-rate/low risk. A theory could start with these simple types of offenders and add postulates about the effects of risk/protective factors and life events in order to explain more and more findings.

It would be desirable to combine a longitudinal study of people with a longitudinal study of places, to try to explain how the individual and the environment interact to produce crimes. It would also be desirable to systematically observe offending as it happens in these places, as Buckle and Farrington (1984) did for shoplifting. More cross-national comparative studies are also needed in order to investigate the replicability of results over time and place and the importance of cultural context and environment.

It would be highly desirable to evaluate the impact of interventions within prospective longitudinal surveys. In order to investigate both the development of offenders and the effectiveness of interventions, longitudinal-experimental studies are 
needed with several years of interviews, then a randomized intervention, and then several more years of interviews. In such a study, hypotheses about the causes of offending could be generated in the longitudinal data and tested both in the experiment and quasi-experimentally by following the same people up before and after a naturally occurring event. For example, the effects of unemployment on offending could be tested both by experimentally evaluating an employment program and by studying the offending of individuals during their periods of employment and their periods of unemployment. To the extent that the findings were similar, this would greatly increase confidence that unemployment really was a cause of offending.

It seems that no large-scale study of this kind has ever been carried out on offending using interview data. Such a project could simultaneously advance knowledge about the development and causes of offending and about the effects of interventions. Also, the impact of interventions can be better understood in the context of pre-existing trends or developmental sequences, and the prior information about participants could make it possible to investigate interactions between types of persons (and their risk/protective factors and prior histories) and types of interventions (Farrington, Loeber, \& Welsh 2010). Long-term follow-up information after an experiment is highly desirable in order to discover effects of an intervention that are not immediately apparent and to compare short-term and long-term effects and investigate developmental sequences that link them.

Nearly 30 years ago, Farrington, Ohlin, and Wilson (1986a) proposed an accelerated longitudinal-experimental design that involved following up four cohorts in a large city, from birth to age 6 , age 6 to age 12 , age 12 to age 18, and age 18 to age 24, with yearly assessments. They suggested testing the effects of preschool and 
parent training interventions in infancy and childhood, peer and school programs at age 15, and employment and drug programs at age 21. It would be desirable to mount this type of a longitudinal-experimental project in Australia or New Zealand, as it would lead to significant advances in knowledge about the development, explanation, prevention, and treatment of offending and antisocial behavior.

The importance of developmental and life-course criminology is increasing rapidly. The Division of the American Society of Criminology on this topic, founded in 2012, quickly grew to have 250 members in 2014. In his Presidential address to this Society, Cullen (2011) essentially argued that developmental and life-course criminology was dominant in criminology, and this view is supported by citation analyses (Cohn, Farrington, \& Iratzoqui, 2014). The time is ripe to advance developmental and life-course criminology in Australia and New Zealand by mounting important new prospective longitudinal surveys. Ideally, an accelerated longitudinal design would be used, since such a design is able to draw on multiple bodies of knowledge and test numerous hypotheses. 


\section{References}

Buckle, A. \& Farrington, D. P. (1984). An observational study of shoplifting. British Journal of Criminology 24, 63-73.

Caspi, A., McClay, J., Moffitt, T. E., Mill, J., Martin, J., Craig, I. W., . . Poulton, R. (2002). Role of Genotype in the Cycle of Violence in Maltreated Children. Science, 297, 851-854.

Cohn, E. G., Farrington, D. P., \& Iratzoqui, A. (2014). Most-cited scholars in criminology and criminal justice, 1986-2010. New York: Springer.

Cullen, F.T. (2011). Beyond adolescence-limited criminology: Choosing our future the 2010 Sutherland Award address. Criminology, 49, 287-330.

Farrington, D. P. (2003). Developmental and life-course criminology: Key theoretical and empirical issues - The 2002 Sutherland Award address. Criminology, 41, 221-255.

Farrington, D. P., Gallagher, B., Morley, L., St Ledger, R.J., \& West, D.J. (1986b). Unemployment, school leaving and crime. British Journal of Criminology, 26, 335-356.

Farrington, D. P., Gallagher, B., Morley, L., St Ledger, R., \& West, D.J. (1990). Minimizing attrition in longitudinal research: Methods of tracing and securing cooperation in a 24-year follow-up study. In D. Magnusson \& L. Bergman (Eds.), Data quality in longitudinal research (pp. 122-147). Cambridge, UK: Cambridge University Press.

Farrington, D. P. \& Koegl, C. J. (2015). Monetary benefits and costs of the Stop Now And Plan program for boys aged 6-11, based on the prevention of later offending. Journal of Quantitative Criminology, in press.

Farrington, D. P., Loeber, R., \& Ttofi, M. M. (2012). Risk and protective factors for offending. In B.C. Welsh \& D.P. Farrington (Eds.), The Oxford handbook of crime prevention (pp. 46-69). Oxford, UK: Oxford University Press.

Farrington, D. P., Loeber, R., \& Welsh, B. C. (2010). Longitudinal-experimental studies. In A. R. Piquero \& D. Weisburd (Eds.), Handbook of quantitative criminology (pp. 503-518). New York: Springer.

Farrington, D. P., Ohlin, L. E., \& Wilson, J. Q. (1986a). Understanding and controlling crime: Toward a new research strategy. New York: Springer-Verlag.

Loeber, R., Farrington, D. P., Stouthamer-Loeber, M., \& White, H. R. (2008). Violence and serious theft: Development and prediction from childhood to adulthood. New York: Routledge.

MacLeod, J. F., Grove, P. G., \& Farrington, D. P. (2012). Explaining criminal 
careers: Implications for justice policy. Oxford, UK: Oxford University Press. 